Proceedings of the 2010 Winter Simulation Conference

B. Johansson, S. Jain, J. Montoya-Torres, J. Hugan, and E. Yücesan, eds.

\title{
USE OF SENSOR EMBEDDED PRODUCTS FOR END OF LIFE PROCESSING
}

\author{
Mehmet Ali Ilgin \\ Surendra M. Gupta \\ Northeastern University \\ 360 Huntington Avenue \\ Boston, MA 02115, USA
}

\begin{abstract}
Sensors embedded into products during the production process have a potential to decrease disassembly yield uncertainty by detecting non-functional or missing components prior to the actual disassembly process. The aim of this study is the quantitative evaluation of the impact of sensor embedded products (SEPs) on the performance of an appliance disassembly line. First, separate design of experiments studies based on orthogonal arrays are performed for the cases with and without SEPs. Discrete event simulation models of both cases were developed to calculate various performance measures under different experimental conditions. Then, the results of pair-wise t-tests comparing the two cases, based on different performance measures, are presented. The results show the superiority of SEPs over conventional products for all performance measures considered in the study.
\end{abstract}

\section{INTRODUCTION}

Product recovery can be defined as the minimization of the amount of waste sent to landfills by recovering materials and parts from returned or end-of-life (EOL) products via recycling and remanufacturing. Dramatic decreases in natural resources and landfills, together with increasing consumer awareness towards environmental issues have increased the importance of product recovery in recent years. Many governments are imposing stricter environmental regulations, some of which require manufacturers to collect and properly dispose of their products at the end of their useful lives. Besides complying with the environmental legislations, manufacturers can also utilize the remaining value in EOL products by establishing specific facilities for product recovery. For a complete review of studies in environmentally conscious manufacturing and product recovery, we refer the reader to surveys by Güngör and Gupta (1999) and Ilgin and Gupta (2010).

The first operation in product recovery is disassembly, which is the systematic separation of desired components, subassemblies, and materials from EOL or returned products. Although different layout types can be used for disassembly operations, the most common layout is the disassembly line due to its high productivity and suitability for automated disassembly. However, there is a high level of uncertainty associated with disassembly line yields since EOL products involve missing and/or nonfunctional components. Moreover, if customers discriminate between the different versions of a component, then the specific version of component must be disassembled from EOL products at a given station. But, determination of the version of a component prior to actual disassembly may not be possible because of the modifications made by the user or the service personnel.

Sensors embedded into products during the production process can improve disassembly yield uncertainty by providing information on the condition and version of critical components before disassembling products. In addition, sensor data can be helpful in the prediction of component or product failures during product lives. 


\section{Ilgin and Gupta}

Although there is a vast amount of literature on the use of sensor-based technologies on after-sale product condition monitoring (Scheidt and Shuqiang 1994; Karlsson 1997; Klausner, Grimm, and Horvath 1999; Petriu et al. 2000), only few researchers have presented a cost-benefit analysis. Klausner, Grimm, and Hendrickson (1998) analyzed the trade-off between the higher initial manufacturing cost caused by the use of an electronic data log in products and cost savings from the reuse of used motors. Simon et al. (2001) improved the cost-benefit analysis of Klausner, Grimm, and Hendrickson (1998) by considering the limited life of a product design. They showed that, in that case, servicing provides more reusable components compared to EOL recovery of parts. Vadde et al. (2008) investigated the effectiveness of embedding sensors in computers by comparing several performance measures in the two scenarios-with embedded sensors and without embedded sensors. However, they do not provide a quantitative assessment of the impact of SEPs on these performance measures. Moreover, since only one component of a computer (hard disk) was considered, the disassembly setting does not represent the complexity of a disassembly line which is generally used to disassemble EOL computers. Ilgin and Gupta (2009) analyzed the effect of SEPs on the performance of an EOL computer disassembly line which is used to disassemble three components from EOL computers, namely, memory, hard disk and motherboard. Due to relatively simple structure of an EOL computer, they did not consider the precedence relationships among the components. However, disassembly of a particular component is restricted by one or more components in some products. That is why these products are disassembled according to a route determined by the precedence relationships. Moreover, the customers may discriminate between different versions of a component.

In this study, we evaluate the quantitative impact of SEPs on the performance of an appliance disassembly line by considering the precedence relationships among the components of a product together with component discriminating demands. First, separate design of experiments studies based on orthogonal arrays are performed for the cases with and without SEPs. Due to the ability of discrete event simulation (DES) in modeling complex disassembly systems (Guide 1993; Gatland, Yang, and Buxton 1997; Ilgin and Gupta 2008), we developed DES models of both cases to calculate various performance measures under different experimental conditions. Then the results of pair-wise t-tests comparing two cases based on different performance measures are presented.

\section{APPLIANCE DISASSEMBLY PROCESS}

A five-station disassembly line is used to disassemble EOL ranges, ovens and cooktops. Figure 1 presents the routing of EOL products together with the components disassembled at different stations of the line. According to this figure, cooktops only visit the last station. EOL ovens visit the first four stations while EOL ranges visit all stations. Disassembly times at stations, demand inter-arrival times (mean time between two successive demands) for components and EOL product inter-arrival times (mean time between two successive EOL product arrivals) are all distributed exponentially.

There are seven components shared by EOL ranges and ovens, namely door, fan plate, fan, lower back plate, motor, upper back plate, circuit board while EOL ranges and cooktops share one common component, namely, heating element. Table 1 presents precedence relationships among the components of a range. Precedence relationships for an oven will be same with a range except for heating element which is not included in ovens. Since only heating element is disassembled from a cooktop, there is no precedence relationship for this product. Various properties of the disassembled components can be seen in Table 2. Customer demand exists for three components, namely, motor, circuit board and heating element. There are two circuit board versions and two heating element versions. The demand arrives for a specific version of a component at a station. For instance, if a customer orders a version 1 circuit board, version 1 circuit board inventory at station 4 is checked. If there is no version 1 circuit board, it is backordered. A version 2 circuit board cannot be used as a substitute for a version 1 circuit board. 


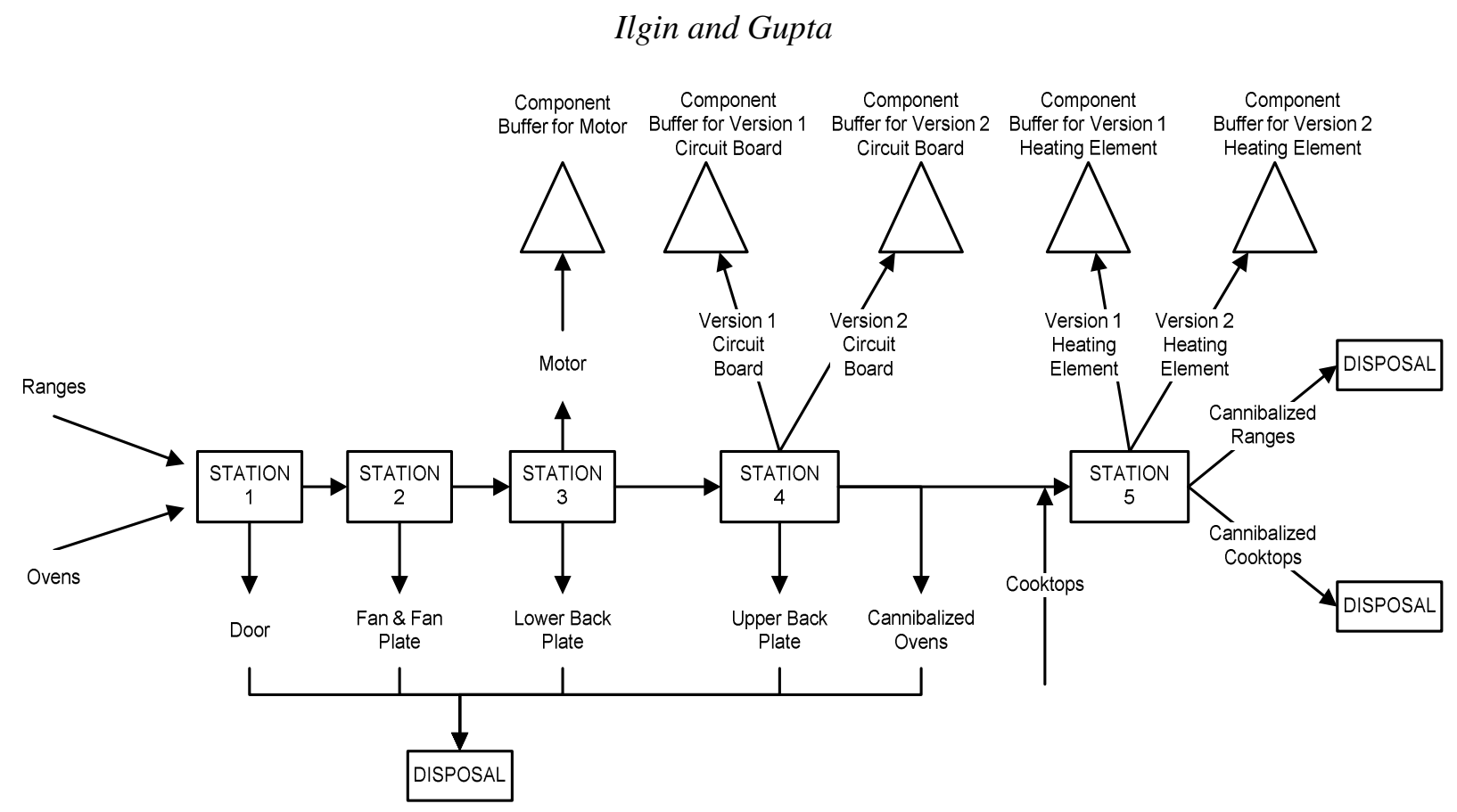

Figure 1: Disassembly of various components from EOL appliances

Table 1: Precedence relationships among the components of a range.

\begin{tabular}{|c|c|c|c|}
\hline Component Name & Code & Precedence Relationship & Station \\
\hline Door & A & - & 1 \\
\hline Fan Plate & B & A & 2 \\
\hline Fan & C & A,B & 2 \\
\hline Lower Back Plate & D & - & 3 \\
\hline Motor & E & A,B,C,D & 3 \\
\hline Upper Back Plate & F & - & 4 \\
\hline Circuit Board & G & F & 4 \\
\hline Heating Element & H & - & 5 \\
\hline
\end{tabular}

Conventional products (ones with no sensors) visit all stations. Following the disassembly at each station, components are tested. Table 2 presents the means and standard deviations for normally distributed testing times of the components. Sensor embedded products visit only the stations which are responsible for the disassembly of the functional components and their predecessor components. In addition, no testing is required for this case because of the sensor information available on the condition of the component.

A small truck with a load volume of 450 cubic is used to dispose of excess products, subassemblies and components. Whenever the total volume of the excess inventories becomes equal to the truck volume, the truck is sent to a recycling facility. Any product, subassembly or component inventory which is greater than maximum inventory level is assumed to be excess. Component volumes are given in Table 2. Cooktop, range and oven volumes are taken as 3, 20, and 20 cubic feet, respectively. A multi kanban system developed by Udomsawat and Gupta (2008) is used to control the disassembly line. 


\section{Ilgin and Gupta}

Table 2: Various specifications for the disassembled components.

\begin{tabular}{|c|c|c|c|c|c|c|}
\hline $\begin{array}{c}\text { Component } \\
\text { Name }\end{array}$ & \multicolumn{2}{|c|}{ Testing Time (min.) } & $\begin{array}{c}\text { Volume } \\
\text { (cft) }\end{array}$ & $\begin{array}{c}\text { Weight } \\
\text { (lbs) }\end{array}$ & Demanded? & $\begin{array}{c}\text { Disposal } \\
\text { Classification }\end{array}$ \\
\hline Door & - & - & 1.15 & $*$ & No & Steel scrap \\
\hline Fan Plate & - & - & 0.02 & 0.3 & No & Steel scrap \\
\hline Fan & - & - & 0.02 & 0.2 & No & Steel scrap \\
\hline Lower Back Plate & - & - & 0.15 & 1 & No & Steel scrap \\
\hline Motor & 12 & 1.5 & 0.02 & $*$ & Yes & Waste \\
\hline Upper Back Plate & - & - & 0.06 & 0.5 & No & Steel scrap \\
\hline Circuit Board & 6 & 1.5 & 0.03 & 0.4 & Yes & Waste \\
\hline Heating Element (Big) & 2.5 & 0.3 & 0.03 & 0.6 & Yes & Waste \\
\hline Heating Element (Small) & 2.5 & 0.3 & 0.02 & 0.3 & Yes & Waste \\
\hline
\end{tabular}

*Door and motor weights are factors in the experimental design study. For the weight ranges defined for these two components, see Table 3.

\section{EXPERIMENTAL DESIGN STUDY}

In this section, we compare the case of SEPs against the case of conventional products (CPs) under different experimental conditions. Table 3 presents the factors and factor levels considered in the experiments. As seen in Table 3, we have 40 factors. A full factorial design with 40 factors would require an extensive number of experiments (viz., 1.22E+19). Therefore, experiments were designed using Orthogonal Arrays (OAs) (Aksoy and Gupta 2005, Dengiz 2009) which allow for the determination of main effects by running a minimum number of experiments. Specifically, $\mathrm{L}_{81} \mathrm{OA}$ was chosen since it requires 81 experiments while accommodating 40 factors with three levels (Phadke 1989).

DES models developed in Arena 11 (Kelton, Sadowski, and Sadowski 2007) were used for both cases to determine profit value together with various cost and revenue parameters for each OA experiment. Animations of the DES models were built for verification purposes. In addition, models' output results were checked for reasonableness. Dynamic plots and counters providing dynamic visual feedback were used to validate the DES models. The replication time for each DES model was 60480 minutes, the equivalent of six months with one eight hour shift per day. DES models were replicated 10 times for each OA experiment.

The following formula is used in the DES models for the calculation of profit values.

$$
\text { Profit }=(\overbrace{S R+C R+S C R}^{\text {Total Revenue }})-(\overbrace{H C+B C+D C+D P C+T C+T P C})
$$

The different cost and revenue components used in the equation 1 can be defined as follows:

- SR : The total revenue generated by the component sales during the simulated time period (STP).

- CR : The total revenue generated by the collection of EOL products during the STP.

- SCR : The total revenue generated by selling scrap components during the STP.

- HC : The total holding cost of components, EOL products and subassemblies during the STP.

- BC : The total backorder cost of components during the STP.

- DC : The total disassembly cost during the STP.

- DPC : The total disposal cost of components, EOL products and subassemblies during the STP.

- TC : The total testing cost during the STP.

- TPC : The total transportation cost during the STP. 


\section{Ilgin and Gupta}

Table 3: Factor levels for the DOE study.

\begin{tabular}{|c|c|c|c|c|c|}
\hline \multirow{2}{*}{ No } & \multirow{2}{*}{ Factor } & \multirow{2}{*}{ Unit } & \multicolumn{3}{|c|}{ Levels } \\
\hline & & & 1 & 2 & 3 \\
\hline 1 & Disposal cost increase factor for EOL products & $\%$ & 4 & 8 & 12 \\
\hline 2 & Scrap revenue decrease factor for EOL products & $\%$ & 4 & 8 & 12 \\
\hline 3 & Mean demand rate for Motor & components/hour & 4 & 8 & 12 \\
\hline 4 & Mean demand rate for Version 1 Circuit Board & components/hour & 2 & 5 & 8 \\
\hline 5 & Mean demand rate for Version 2 Circuit Board & components/hour & 2 & 5 & 8 \\
\hline 6 & Mean demand rate for Version 1 Heating Element & components/hour & 6 & 8 & 10 \\
\hline 7 & Mean demand rate for Version 2 Heating Element & components/hour & 6 & 8 & 10 \\
\hline 8 & Mean arrival rate of EOL Ranges & products/hour & 12 & 16 & 20 \\
\hline 9 & Mean arrival rate of EOL Ovens & products/hour & 5 & 10 & 15 \\
\hline 10 & Mean arrival rate of EOL Cooktops & products/hour & 2 & 5 & 8 \\
\hline 11 & Mean disassembly time for station 1 & minutes & 0.30 & 0.60 & 0.90 \\
\hline 12 & Mean disassembly time for station 2 & minutes & 0.60 & 0.80 & 1 \\
\hline 13 & Mean disassembly time for station 3 & minutes & 0.60 & 0.80 & 1 \\
\hline 14 & Mean disassembly time for station 4 & minutes & 0.60 & 0.80 & 1 \\
\hline 15 & $\begin{array}{l}\text { Mean disassembly time for a heating element at } \\
\text { station } 5\end{array}$ & minutes & 0.15 & 0.20 & 0.25 \\
\hline 16 & Backorder cost rate & $\%$ & 35 & 55 & 75 \\
\hline 17 & Unit disassembly cost & $\$ /$ minute & 0.8 & 1.6 & 2.4 \\
\hline 18 & Unit testing cost & $\$ /$ minute & 0.45 & 0.55 & 0.65 \\
\hline 19 & Holding cost rate & $\%$ & 12 & 24 & 36 \\
\hline 20 & Weight for Door & lbs & 20 & 25 & 30 \\
\hline 21 & Weight for Motor & lbs & 4 & 8 & 12 \\
\hline 22 & Weight of other steel components of Oven or Range & lbs & 180 & 200 & 220 \\
\hline 23 & Weight of other steel components of Cooktop & lbs & 25 & 35 & 45 \\
\hline 24 & Price for Motor & $\$$ & 45 & 70 & 95 \\
\hline 25 & Price for Version 1 Circuit Board & $\$$ & 35 & 55 & 75 \\
\hline 26 & Price for Version 2 Circuit Board & $\$$ & 15 & 35 & 55 \\
\hline 27 & Price for Version 1 Heating Element & $\$$ & 15 & 25 & 35 \\
\hline 28 & Price for Version 2 Heating Element & $\$$ & 6 & 12 & 18 \\
\hline 29 & Unit disposal cost & $\$ /$ lbs & 0.25 & 0.35 & 0.45 \\
\hline 30 & Unit steel scrap revenue & \$/lbs & 0.16 & 0.20 & 0.24 \\
\hline 31 & Maximum inventory level & $\begin{array}{l}\text { Component or } \\
\text { subassembly or } \\
\text { product }\end{array}$ & 6 & 12 & 18 \\
\hline 32 & Small component weight factor & $\%$ & 4 & 8 & 12 \\
\hline 33 & Probability of a non-functional Motor & $\%$ & 15 & 25 & 35 \\
\hline 34 & Probability of a non-functional Circuit Board & $\%$ & 15 & 25 & 35 \\
\hline 35 & Probability of a non-functional Heating Element & $\%$ & 15 & 25 & 35 \\
\hline 36 & Probability of a missing Motor & $\%$ & 10 & 15 & 20 \\
\hline 37 & Probability of a missing Circuit Board & $\%$ & 10 & 15 & 20 \\
\hline 38 & Probability of a missing Heating Element & $\%$ & 10 & 15 & 20 \\
\hline 39 & Probability of a Version 1 Circuit Board & $\%$ & 30 & 50 & 70 \\
\hline 40 & Probability of a Version 1 Cooktop or Range & $\%$ & 30 & 50 & 70 \\
\hline
\end{tabular}




\section{Ilgin and Gupta}

In each oven and range, chassis, door, fan plate, fan, upper back plate, lower back plate are sold as steel scrap while chassis is regarded as steel scrap in a cooktop. All the other components in a product are considered as waste components. In order to determine the total weight of small components such as screws and cables, total weight of the main components of a product is multiplied by a small component weight factor (these small components are considered as waste components.)

In order to calculate the disposal cost of a waste component, the weight in pounds is multiplied by the disposal cost per pound. Disposal costs for subassemblies and products are calculated by multiplying the total weight of waste components in a subassembly or product by the disposal cost per pound. Disposal costs for subassemblies and products are increased by a factor called disposal cost increase factor for EOL products. The nuisance created by the disposal of subassemblies and products is higher than that of components because they may involve hazardous materials.

Scrap revenue from a component is calculated by multiplying the weight in pounds by the scrap revenue per pound. In the calculation of scrap revenue for subassemblies and products, total weight of scrapable components in a subassembly or product is multiplied by the scrap revenue per pound. Scrap revenues for subassemblies and products are decreased by a factor called scrap revenue decrease factor for EOL products, which considers the cost of operations required for the separation of materials from them.

While estimating the testing costs for SEPs, the time required to retrieve information from the sensors prior to disassembly is assumed to be 20 seconds per product. In the calculation of transportation cost, the operating cost associated with each trip of the truck is assumed to be $\$ 60$. For each EOL oven or range, the facility gets a $\$ 15$ collection fee while the collection fee for cooktops is $\$ 7.5$.

\section{RESULTS}

Design of experiments study presented in Section 3 was run for SEPs and CPs. Table 4 presents the 95\% confidence interval, $t$-value and p-value for each test. According to this table, SEPs achieve statistically significant savings in holding, backorder, disassembly, disposal, testing and transportation costs. Moreover, there are statistically significant improvements in total revenue and profit for the case of SEPs.

Table 4: Results of pair-wise t-tests

\begin{tabular}{|l|c|c|c|}
\hline $\begin{array}{c}\text { Performance } \\
\text { Measure }\end{array}$ & $\begin{array}{c}\text { 95\% Confidence Interval on Mean Difference } \\
\text { (Sensor -No Sensor) }\end{array}$ & t-value & p-value \\
\hline Holding Cost & $(-24.8366,-12.1301)$ & -5.79 & 0.000 \\
\hline Backorder Cost & $(-605.856,-462.172)$ & -14.79 & 0.000 \\
\hline Disassembly Cost & $(-39669.3,-26348.4)$ & -9.86 & 0.000 \\
\hline Disposal Cost & $(-55070.5,-46206.0)$ & -22.74 & 0.000 \\
\hline Test Cost & $(-113479,-96697)$ & -24.92 & 0.000 \\
\hline Transportation Cost & $(-5350.51,-3983.41)$ & -13.59 & 0.000 \\
\hline Total Cost & $(-208569,-179340)$ & -26.41 & 0.000 \\
\hline Total Revenue & $(190207,250264)$ & 14.60 & 0.000 \\
\hline Profit & $(383554,444827)$ & 26.90 & 0.000 \\
\hline
\end{tabular}

\section{CONCLUSIONS}

Stricter environmental regulations coupled with increasing environmental awareness of consumers are putting pressure on manufacturers. In order to comply with these regulations and to have a better environmental image, many manufacturers set up specific facilities for product recovery. Disassembly is an important process in product recovery, since all product recovery options require some level of product 


\section{Ilgin and Gupta}

disassembly. However, there is a high level of uncertainty associated with disassembly yields due to defective and/or missing components and unknown component versions. In order to deal with this problem, in this study, we proposed and analyzed the use of sensors in the detection of failed and/or missing components and in the determination of component versions in a product before disassembling it. First, separate designs of experiment studies based on orthogonal arrays were performed for conventional products and SEPs. Then, the results of pair-wise t-tests comparing the two cases, based on different performance measures were presented. The test results indicate that SEPs can provide higher revenue and profit levels while decreasing holding, backorder, disassembly, transportation and test costs.

In this study, it is assumed that all sensors in an EOL product are functional and they are providing right information on the condition and version of the components. However, during the product usage, the sensors may malfunction. They may stop working or they may provide wrong information. Analysis of the impact of SEPs on the performance of a product recovery system considering faulty sensors in EOL products will be an interesting future research topic.

\section{REFERENCES}

Aksoy, H.K., and S.M. Gupta. 2005. Buffer allocation plan for a remanufacturing cell. Computers \& Industrial Engineering 48: 657-677.

Dengiz, B. 2009. Redesign of PCB production line with simulation and Taguchi design. In Proceedings of the 2009 Winter Simulation Conference, 2197-2204. Austin, TX.

Gatland, R., E. Yang, and K. Buxton. 1997. Solving engine maintenance capacity problems with simulation. In Proceedings of the 1997 Winter Simulation Conference, 892-899. Atlanta, GA.

Güngör, A., and S.M. Gupta. 1999. Issues in environmentally conscious manufacturing and product recovery: A survey. Computers \& Industrial Engineering 36: 811-853.

Guide, V.D.R. 1993. A simulation of synchronous manufacturing at a naval aviation depot. In Proceedings of the 1993 Winter Simulation Conference, 908-915. Los Angeles, CA.

Ilgin, M.A., and S.M. Gupta. 2008. Joint optimization of transportation and spare parts inventory policies in a reverse logistics network using OptQuest In Proceedings of the 2008 ASME International Mechanical Engineering Congress and Exposition, 877-885. Boston, MA.

Ilgin, M.A., and S.M. Gupta. 2009. Analysis of a kanban controlled disassembly line with sensor embedded products. In Proceedings of the 2009 Northeast Decision Sciences Institute Conference, 555-560. Uncasville, Connecticut.

Ilgin, M.A., and S.M. Gupta. 2010. Environmentally conscious manufacturing and product recovery (ECMPRO): A review of the state of the art. Journal of Environmental Management 91: 563-591.

Karlsson, B. 1997. A distributed data processing system for industrial recycling. In Proceedings of 1997 IEEE Instrumentation and Measurement Technology Conference, 197-200 Ottawa, Canada.

Kelton, D.W., R.P. Sadowski, and D.A. Sadowski. 2007. Simulation with arena. 4th ed. New York: McGraw-Hill.

Klausner, M., W.M. Grimm, and C. Hendrickson. 1998. Reuse of electric motors in consumer products. Journal of Industrial Ecology 2: 89-102.

Klausner, M., W.M. Grimm, and A. Horvath. 1999. Integrating product takeback and technical service. In Proceedings of the 1999 IEEE International Symposium on Electronics and the Environment, 4853. Danvers, MA.

Petriu, E.M., N.D. Georganas, D.C. Petriu, D. Makrakis, and V.Z. Groza. 2000. Sensor-based information appliances. IEEE Instrumentation \& Measurement Magazine 3: 31-35.

Phadke, M.S. 1989. Quality engineering using robust design. New Jersey: Prentice Hall.

Scheidt, L., and Z. Shuqiang. 1994. An approach to achieve reusability of electronic modules. In Proceedings of the 1994 IEEE International Symposium on Electronics and the Environment, 331-336. San Francisco, CA. 


\section{Ilgin and Gupta}

Simon, M., G. Bee, P. Moore, J.-S. Pu, and C. Xie. 2001. Modelling of the life cycle of products with data acquisition features. Computers in Industry 45: 111-122.

Udomsawat, G., and S.M. Gupta. 2008. Multikanban system for disassembly line. In Environment conscious manufacturing, S.M. Gupta and A.J.D. Lambert eds, 311-330. Boca Raton, FL: CRC Press.

Vadde, S., S. Kamarthi, S.M. Gupta, and I. Zeid. 2008. Product life cycle monitoring via embedded sensors. In Environment conscious manufacturing, S.M. Gupta and A.J.D. Lambert eds, 91-103. Boca Raton, FL: CRC Press.

\section{AUTHOR BIOGRAPHIES}

MEHMET ALI ILGIN is a Ph.D. candidate in Mechanical and Industrial Engineering Department of Northeastern University in Boston. He received his B.Sc. and M.Sc. degrees in industrial engineering from Dokuz Eylül University, Turkey. His research interests are in the areas of environmentally conscious manufacturing, product recovery, reverse logistics, spare parts inventory management and simulation. His recent activities can be viewed at <http://kisi.deu.edu.tr/mehmetali.ilgin/>. His email address is <mehmetali.ilgin@deu.edu.tr $>$.

SURENDRA M. GUPTA is a Professor of Mechanical and Industrial Engineering and Director of the Laboratory for Responsible Manufacturing at Northeastern University in Boston. He received his B.E. in electronics engineering from Birla Institute of Technology and Science, M.B.A. from Bryant University, and M.S.I.E. and Ph.D. in industrial engineering from Purdue University. His research interests are in the areas of production/manufacturing systems and operations research. He is mostly interested in environmentally conscious manufacturing, electronics manufacturing, MRP, JIT, and queueing theory. He has authored and coauthored over 400 technical papers published in prestigious journals, books, and conference proceedings. His publications have been cited by thousands of researchers all over the world in journals, proceedings, books, and dissertations. He has traveled to all seven continents and presented his work at international conferences there (except Antarctica). He is currently serving as the Area Editor of Environmental Issues for Computers and Industrial Engineering, Associate Editor for the International Journal of Agile Systems and Management and editorial board member of a variety of journals. He has also served as Conference Chair, Track Chair, and member of Technical Committees of a variety of international conferences. Dr. Gupta has been elected to the memberships of several honor societies and is listed in various Who's Who publications. He is a registered Professional Engineer in the State of Massachusetts and a member of ASEE, DSI, IIE, INFORMS, and POMS. Dr. Gupta is a recipient of the Outstanding Research Award and the Outstanding Industrial Engineering Professor Award (in recognition of Teaching Excellence) from Northeastern University. His recent activities can be viewed at $<$ http://www1.coe.neu.edu/ smgupta/>. His email address is <gupta@neu. edu> . 